University of Nebraska - Lincoln

DigitalCommons@University of Nebraska - Lincoln

$1-21-2020$

Do People Really Become More Conservative as They Age?

Johnathan C. Peterson

Kevin Smith

John Hibbing

Follow this and additional works at: https://digitalcommons.unl.edu/poliscifacpub

Part of the Political Science Commons

This Article is brought to you for free and open access by the Political Science, Department of at

DigitalCommons@University of Nebraska - Lincoln. It has been accepted for inclusion in Faculty Publications:

Political Science by an authorized administrator of DigitalCommons@University of Nebraska - Lincoln. 


\title{
Do People Really Become More Conservative as They Age?
}

\author{
Johnathan C. Peterson, Palo Alto College \\ Kevin B. Smith, University of Nebraska-Lincoln \\ John R. Hibbing, University of Nebraska-Lincoln
}

Folk wisdom has long held that people become more politically conservative as they grow older, although several empirical studies suggest political attitudes are stable across time. Using data from the Michigan Youth-Parent Socialization Panel Study, we analyze attitudinal change over a major portion of the adult life span. We document changes in party identification, self-reported ideology, and selected issue positions over this time period and place these changes in context by comparing them with contemporaneous national averages. Consistent with previous research but contrary to folk wisdom, our results indicate that political attitudes are remarkably stable over the long term. In contrast to previous research, however, we also find support for folk wisdom: on those occasions when political attitudes do shift across the life span, liberals are more likely to become conservatives than conservatives are to become liberals, suggesting that folk wisdom has some empirical basis even as it overstates the degree of change.

O ne of the most widespread generalizations among social scientists and the lay public is that people become more conservative as they grow older (Glenn 1974). This belief is captured in the well-known aphorism that "if you are not a liberal at 20 you have no heart and if you are not a conservative at 30 you have no brain," variants of which date from at least the time of the French Revolution. Voting patterns seem to confirm the relationship between aging and conservativism. For example, exit polls suggest just $37 \%$ of $18-$ 29-year-old voters cast a ballot for Donald Trump in the 2016 presidential election, compared to $43 \%$ of $30-44$-year-old voters and $53 \%$ of those over 45 . Despite the broad acceptance of this folk wisdom, in the scholarly literature the theoretical foundations linking aging to shifts in political attitudes are somewhat inconsistent, and empirical support is, at best, mixed. Our goal in this article is to examine the theoretical models for expecting aging to lead to a more conservative political orientation and to provide a robust empirical test of this relationship.

\section{THEORY AND LITERATURE}

Why is aging so often expected to produce a conservative shift? Aspects of aging include psychological aging, physio- logical aging, social aging, biological aging, economic aging, and aging in and of itself. A theoretical basis for expecting a rightward drift in political views can be constructed from nearly all of these. Psychological and physiological age-related changes, for example, include increasing self-discipline, preference for order, uncertainty avoidance, the capacity to remember emotionally laden stimuli, and alterations in neural structures (Dennis et al. 2008; Jost et al. 2007; St. Jacques, Dolcos, and Cabeza 2009). All of these can plausibly be connected to personality characteristics, such as greater conscientiousness and diminished openness to new experiences, frequently associated with conservatism (Gerber et al. 2010; Mondak 2010; Soto et al. 2011; Srivastava et al. 2003). Such psychological and personality changes could lead to endorsement of more authoritarian and traditional values and norms (Cornelis et al. 2009) and perhaps even higher levels of prejudice (Henry and Sears 2009).

Social aging refers to changes in patterns of social interactions across the life course. From the twenties to the fifties, social patterns are often dominated by increasing familial connections, while retirement from the workforce in the sixties may be accompanied by a rapid decline in overall

Johnathan C. Peterson (jpeterson71@alamo.edu) is an assistant professor of government at Palo Alto College, San Antonio, TX 78224. Kevin B. Smith (ksmith1@unl.edu) and John R. Hibbing (jhibbing1@unl.edu) are professors of political science at University of Nebraska-Lincoln, Lincoln, NE 68588.

Data and supporting materials necessary to reproduce the numerical results in the article are available in the JOP Dataverse (https://dataverse.harvard.edu /dataverse/jop). An online appendix with supplementary material is available at https://doi.org/10.1086/706889.

The Journal of Politics, volume 82, number 2. Published online January 21, 2020. https://doi.org/10.1086/706889

(C) 2020 by the Southern Political Science Association. All rights reserved. 0022-3816/2020/8202-0014\$10.00 
social interactions. These sorts of changes in social opportunities and obligations could affect values and approaches to life that are related to politics. For example, evidence suggests that people in middle age care more about their work, their responsibilities, and their family, and these tendencies may direct attention toward more immediate, personal concerns (Angel and Settersten 2012; Srivastava et al. 2003). Such a growing focus on immediate, personal matters could facilitate a pattern consistent with folk wisdom, as middle-aged individuals lose some of the idealism that might have been present before the assumption of family and work responsibilities (Glenn 1974).

Changes in economic status also frequently accompany aging. Financial resources tend to grow with time spent in the workforce and accumulate as a career gathers momentum. An increase in resources during the movement into middle age might lead some to develop greater appreciation for a stable, predictable, secure society and also to embrace laissezfaire stances on taxation and redistribution (Angel and Settersten 2012). Retirement can also bring a shift in economic status, a change that may have important implications for political attitudes and behavior. For example, there is good evidence that the importance of Social Security to the financial well-being of senior citizens is an important motivator of their political attitudes and actions (Campbell 2002).

Biological aging occurs throughout the life course, and we already mentioned the gradual shifts in neural functioning that could be connected to conservatizing tendencies. But, major and often rapid late-in-life changes like health declines can dramatically affect lifestyle and motility (Sears 1981). Unlike the other effects of aging we have discussed, serious health needs may shift some political views to the left. Although we do not know of any empirical evidence on this point, as health deteriorates in advanced years the need for assistance from others, including the government, increases and could lead to support for interventionist, redistributive health care policies.

Yet another aspect of aging is simply the passage of the years themselves. Even if an individual's psychological, social, economic, and health situations were somehow to remain constant, the fact remains that every year brings more experiences. This means that each subsequent event is mathematically an inevitably smaller proportion of the summation of life's previously accumulated experiences. As a result, the passage of the years may bring what appears to be a greater reluctance to change in light of new events and a greater weddedness to what has come before (Glenn 1974).

In sum, aging brings a complicated web of changes, but theoretical reasoning and previous scholarship suggests that on balance aging can be expected to push many toward the political right. However, there are reasons to be cautious about overgeneralizing aging's impact on political drift. First, individual variation in the components of the aging process is enormous. For example, certainly not all people see their financial status improve as their lives unfold. Second, linearity should not be assumed; as mentioned above, social connections and exposures tend to increase into middle age but then decrease after retirement with similar patterns possible for financial status as well as other variables (see Danigelis, Hardy, and Cutler 2007). Third, the case for expecting a conservative shift is not equally strong with regard to all categories of political issues, making it possible for the results of aging to be different for stances on social as opposed to economic issues.

The most important reason for caution, however, may be that two very different conceptualizations of conservatism can be found in the literature on politics and aging. The first is the classic Burkean formulation entailing active endorsement of policies designed to promote the existing social order. This means favoring policies supporting that social order and countering threats to it by norm violators and out-groups. The second meaning of conservatism is less concerned with the substantive policy positions than the degree to which an individual clings to beliefs. Reluctance to change is a distinct view of conservatism in that it suggests someone who settles into increasingly inflexible left-of-center stances is also demonstrating conservatism in a certain sense of the word (for a discussion of these two aspects of conservatism, see Jost et al. [2003]). Depending on which conceptualization of conservatism is being employed, quite different answers regarding the aging-conservatism connection may be produced.

To add to the confusion, empirical work on the relationship between aging and political orientations varies depending on disciplinary focus. Political scientists have largely explored the degree of stability of political attitudes with only minimal attention to the direction of any movement that does occur (e.g., Campbell et al. 1960; Converse 1964; Jennings and Markus 1984). Scholars in sociology, psychology, and gerontology, however, have been more interested in the direction of movement - that is, in whether people generally move toward more conservative postures (e.g., Cornelis et al. 2009; Danigelis et al. 2007).

Turning first to the political science literature, at least five prevailing theories are in evidence. The lifelong persistence model, derived primarily from the work of Campbell et al. (1960), suggests that political attitudes result from socialization early in life and then persist throughout the life span despite new political shocks and information. Although primarily applied to party identification, the lifelong persistence model also provides testable hypotheses for issue attitude change and related concepts. 
The impressionable years model argues that young adults, roughly between the ages of 18 and 26 , are susceptible to attitudinal change but that thereafter attitudes crystallize and become increasingly immune to new information as the years go on (Alwin, Cohen, and Newcomb 1991; Alwin and Krosnick 1991; Jennings and Markus 1984; Jennings and Niemi 1981; Markus 1979; Newcomb 1943; Newcomb et al. 1967; Niemi and Jennings 1991; Sears and Funk 1999; Stoker and Jennings 2008). In sum, the impressionable years model suggests that people are pliable in early adulthood but relatively stable after that (Dinas 2013).

Other models allow for the possibility of more change throughout the life span. The party loyalty model holds that individuals have no stable or fixed opinions separate from their partisan loyalty. In other words, this model implies that after controlling for party identification, attitudes are correlated as if individuals were expressing issue positions more or less at random (see Achen and Bartels 2016; Page and Shapiro 1992; Zaller 1992).

The lifelong openness model suggests that attitudes remain equally responsive to new information and events throughout the life span. This model is most succinctly presented by Franklin and Jackson (1983) and Franklin (1984) who found that partisan identification was responsive to the ever-changing policy orientations of the Democratic and Republican parties. Presumably, the direction of the change would depend on the nature of the evolving political environment.

The running tally model is a rational choice approach to political learning primarily developed by Fiorina (1981) and expanded on by Achen (2002) and Gerber and Green (1998). This approach suggests that people routinely update their attitudes on the basis of retrospective (Fiorina 1981; Gerber and Green 1998) or prospective (Achen 2002) evaluations of the political environment. Similar to the lifelong openness model, the running tally model allows for attitudes to fluctuate throughout the life span. Contrary to the lifelong openness model, the running tally model accords a large role to prior attitudes, and they are expected to continue to be factored into constantly accumulating "tallies."

An interesting feature of all the models in the political science literature is that none are directional. In other words, none of them directly addresses the veracity of the claim that a conservative shift accompanies aging, except in the sense that no significant aging-related conservative shift is possible if orientations are completely stable through the years (lifelong persistence) or largely stable after an early and ephemeral period of flux (impressionable years). To put it another way, none of these models predicts or expects an inherent bias toward conservative rather than liberal change. In this sense the political science literature tends to focus on the degree rather than the direction of change, with most of the results pointing toward a substantial amount of stability as aging occurs.

In contrast, on the basis of the changes accompanying aging, the literature in other disciplines displays significantly greater interest in the direction of change, with the common expectation and finding being that for a variety of politically relevant issues the direction of change observed will be toward the right rather than the left (see Cornelis et al. 2009; Franssen, Dhont, and Van Hiel 2013; Kossowska, Jaśko, and Bar-Tal 2012; Tilley and Evans 2014; Van Hiel and Brebels 2011; Wilson 1973; although see Schwadel and Garneau 2014). As such, these results seem to support folk wisdom.

In summary, the existing literature exhibits no shortage of theoretical models linking aging to political attitudes. Broadly speaking, those models focus on direction or stability (but not both) and have discordant expectations. Direction focused theoretical frameworks, mainly developed outside political science, generally (but not uniformly) suggest that various aspects of the aging process (psychological aging, economic aging, etc.) support conventional wisdom in predicting a rightward drift over the life span. The bulk of stability focused models developed in political science argue for long-term stasis in political attitudes or at least partisanship throughout adulthood (lifelong persistence, impressionable years, party loyalty), although there are clearly counterarguments for instability (lifelong openness, running tally). What might a coherent combination of all these disparate theoretical arguments look like? A reasonable synthesis is a model that predicts a general stability in political attitudes, at least once out of early adulthood, but allows for change and predicts that any such change is more likely to move in a conservative rather than a liberal direction. Such a synthesis clearly captures the dominant theoretical arguments relating to direction, while also incorporating political science work arguing for stability.

This model suggests a set of straightforward hypotheses: (1) Political attitudes will remain relatively stable across adulthood. (2) Over the long term, any change in attitudes that does occur will more likely be to the political right rather than the political left. Finding these patterns would support our synthesized model. To the best of our knowledge, these hypotheses have never been simultaneously tested. If an empirical analysis fails to support either hypothesis - that is, if attitudes are unstable and move equally in both directions - it would suggest two of the models championed in political science (lifelong openness, running tally) are the stronger theoretical accounts of the link between aging and political attitudes. A clear move to the left would constitute an empirical result with very little theoretical basis. 


\section{THE CHALLENGES OF THEORY TESTING}

A huge obstacle to empirically assessing the relationship between aging and political attitudes is data availability. Ideally, testing hypotheses on aging and political orientations requires a data set containing longitudinal information on political views across the adult lifetime for many people in many different cohorts. Yet long-term longitudinal data sets for even a single cohort are rare, which is undoubtedly why most research has used cross-sectional data (Cornelis et al. 2009; Danigelis et al. 2007; Franssen et al. 2013; Glenn 1974; Grant et al. 2001; Kossowska et al. 2012; Schwadel and Garneau 2014; Searing, Wright, and Rabinowitz 1976; Van Hiel and Brebels 2011).

The problem with using cross-sectional data is that they are obviously ill equipped to identify life-cycle effects. Just because older people are more conservative than younger people at any given time does not mean that people have become more conservative as they age. After all, many factors other than the process of aging could account for persistent positive cross-sectional correlations between age and conservatism. Perhaps liberals tend to pass away at a younger age than conservatives. Perhaps liberals are more likely to quit answering survey requests as they get older. Perhaps society itself became more liberal over time (for evidence that this may indeed be the case, see Schwadel and Garneau [2014]), making it appear as though individuals themselves changed when in fact individuals were largely static while the world evolved around them. Or perhaps over-time changes occurred in a third variable (e.g., increases in mean years of education and especially in college attendance) that is related both to political beliefs and to age, which then might give the impression of growing conservatism when it is really just the case that the older people in a cross-section were less likely to have, say, extended education. In short, standard crosssectional data confound aging effects with period effects (for a thorough discussion of these and related issues, see Firebaugh [1997] and Yang and Land [2013]).

In the absence of longitudinal data, several scholars have turned to synthetic or constructed cohort analysis (e.g., Alwin 1994). Advantages accrue to such an approach, but it typically relies on the assumption that the only causes of attitudinal change within a cohort are the result of intracohort aging/ learning and not attrition from the cohort (Danigelis et al. 2007). The assumption of no attrition would be less concerning except for recent evidence of systematic differences in mortality rates for liberals and conservatives (see Pabayo, Kawachi, and Muennig 2015; Subramanian, Huijts, and Perkins 2009; Subramanian et al.2010). So while cohort analyses have provided many useful insights, authoritatively adjudicating between life cycle and either generational or period effects requires real longitudinal data, preferably spanning several decades.
This reality has led some scholars to turn toward data that follow individuals across major portions of their lives. Such data are still not perfect because any given cohort may not be typical, meaning that results could have been much different with a cohort from an earlier or later time period. Still, the ability to see changes in a given cohort at multiple life stages is a real advantage and makes it possible to document political changes over the course of a lifetime for that cohort at least. One problem is that few data sets measure political beliefs for the same people during periods of time longer than a few years. To be more specific, as far as we are aware, only three publicly accessible, long-term longitudinal data sets contain the information necessary to assess the degree and nature of political change over the course of a significant portion of the life span: the Bennington Study, the Terman Study, and the Michigan Youth-Parent Socialization Panel Study (MSS).

The Bennington Study began as an investigation of attitude change among approximately 500 students attending Bennington (VT) College - at that time an all-female institution-in the late 1930s. In 1960, 350 of the Bennington women were reinterviewed to see whether the changes had persisted and then, in 1984, when most of the women were in their late sixties, 266 again were reinterviewed. The items posed in these interviews included nine dealing with specific social and economic issue attitudes (for a valuable summary, see Alwin et al. [1991]).

The Terman Study began in the early 1920s when Stanford psychologist Lewis Terman identified and tested approximately 1,500 intellectually gifted high school students. Mail questionnaires were completed by an impressive number of the original participants in 1940, 1950, 1960, and 1977. Political information - usually only party identification and selfreported ideology - was not contained in the original data collection, so the useful period covered is approximately 37 years, from about the time participants were in their early thirties until when they were approximately 70 years of age (for more details, see Sears and Funk [1999]).

The dominant analytic approach in this literature correlates an individual's attitudes in previous waves with attitudes in subsequent waves, using either standard correlations, continuity coefficients, or test-retest statistics (see, e.g., Jennings, Stoker, and Bowers 2009; Sears and Funk 1999). The central finding with regard to the effects of aging on political orientations is that a significant amount of stability in views is present.

Although variants of continuity coefficients are perfectly appropriate if the topic of interest is persistence, they only afford indications of the degree of change (in other words, of the extent to which views at, e.g., age 25 correlate with the same person's views at age 40). Surprisingly little attention in political science has been given to the direction of change as 
opposed to the degree of change (for a brief exception, see Sears and Funk [1999], 10). We should note in passing that some scholars have been interested in the distinct but related matter of changes in levels of political participation and interest (see, e.g., Green and Shachar 2000; Walsh, Jennings, and Stoker 2004). When, as is the case in this article, the focus is on political preferences, the main area of scholarly concern has tended to be on changes in party identification, with ideology and individual issues getting much briefer attention. Stoker and Jennings (2008), for example, focused on changes over time in the link between party identification and issue positions, and Sears and Funk (1999) analyzed changes in issue salience.

The sample characteristics for both of these longitudinal data sets (females attending an exclusive college in the Northeast and extremely gifted high school students in California) urge caution when generalizing. Given the atypical nature of these two samples, we were attracted to the third longitudinal data set: the MSS. These data have been described in great detail in other work (see Jennings and Niemi 1981; Jennings et al. 2005) and afford a unique opportunity to study attitudinal change. The MSS was initiated by surveying 1,669 high school seniors and their parents in 1965. (We should note that, since in the mid-1960s many students would have dropped out of high school before their senior year, even this sample is certainly not perfectly representative.) The study then reinterviewed those same people in 1973,1982, and then again in 1997, when the researchers not only returned to the original youth cohort but also interviewed their children. We focus here on the individuals who were high school seniors in 1965 since they provided the most complete information, although even here data are not available across the entire time span of the survey. For example, ideological self-identification was not asked in 1965, although it was in the other three waves.

A total of 935 of the original respondents were reinterviewed in the final, mid-1997 wave, an impressive retention rate of 56\% from the original pool. In 1997 about half of the interviews were face to face and half by telephone, while the data from the three prior waves were mostly collected through face-to-face interviews. All interviews were conducted by the Survey Research Center of the University of Michigan (see Jennings et al. [2009] for more details). The nature of this data set provides advantages for studying change in political orientations. These data are truly longitudinal and cover the years of life from ages 18 to approximately 50, making it possible to examine sources of attitudinal change over the course of an important and lengthy segment of the adult life span - a segment that includes the alleged change from idealistic 20 -yearolds to coldly rational 30 -year-olds that is the basis for so much folk wisdom and scholarly analysis. Still, we readily admit that these data do not provide insight into changes in political orientations during later stages of the life cycle. These changes are undeniably important and should not be assumed to be merely a continuation of the nature and direction of changes occurring earlier.

As noted above, our operational theory combines the emphases of the political science tradition stressing stability in political beliefs across the life span with the tradition apparent in other disciplines stressing the existence of a conservative shift with age. We assert that stability in views will be quite common. This expectation is consistent with long-standing findings in political science, going back at least to Converse, as well as with more psychologically and biologically based assertions that people have relatively stable, politically relevant predispositions that are difficult but not impossible to change (Hibbing, Smith, and Alford 2014). At the same time, our theory recognizes that not everyone remains perfectly stable. Previous work on the nature of aging is convincing in suggesting that, for psychological and other reasons, pressure toward the political right will be greater than toward the left. Therefore, we expect that on those occasions when stability is not in evidence individuals will be significantly more likely to become more conservative than more liberal.

To put it differently, consistent with a substantial amount of political science research, we predict that most people's political orientations in early adulthood will be accurate predictors of their orientations at least until late middle age but, consistent with folk wisdom and research in other disciplines, we expect that the movement occurring will not be balanced. Aging does entail conservatizing tendencies; it is just that these tendencies are usually not powerful enough to override inertial forces. As such, our model combines the known persistence of political beliefs with the conservatizing pressures believed to accompany the aging process (e.g., Sears and Funk 1999; Sears and Valentino 1997).

Testing these expectations could facilitate important advances in theoretical understanding of the nature and sources of political orientations. If a shift to the right with aging is detected, it would suggest that the next step for researchers will be sorting through each of the many features of aging that could be the reason for the conservatizing pattern. If, however, aging does not bring a shift to the right, this would suggest that the substantial theoretical bases for expecting such a relationship need to be reconsidered. What are the actual consequences of aging for the two conceptualizations of conservatism-over-time stability in beliefs and embracing Burkean issue positions? Looking at this question from a cross-sectional perspective is useful, but observing key variables unfold throughout the course of actual lives holds the promise of providing more revealing answers.

Moreover, the evidence is strong that on a range of important issues, such as attitudes toward the death penalty and 
corporal punishment as well as tolerance for interracial marriage, females in nontraditional roles, and gay rights (Schwadel and Garneau 2014), public opinion as a whole has become more liberal in recent decades even as at any given point older people tend to have more conservative positions than younger people on these issues. What will happen if society's shift to the left on selected issues does not continue? If it is the aging process that produces conservatism, older people will continue to be more conservative than their younger colleagues. If, however, older people have not become more conservative with age but rather have merely continued to hold the beliefs they did when they were 20 years old-beliefs that decades later might appear to be conservative - then the apparent conservatizing effects of age would be misleading, and older people would no longer appear to be more conservative. The question becomes whether, if society's drift to the left stopped, older people would eventually cease being more conservative than young people. We propose to determine whether the apparent tendency of aging to shift political beliefs to the right is largely due to the practice of confusing the effects of aging with the effects of age.

\section{AGGREGATE RESULTS}

For our purposes, the key limitation of the MSS data is that only a few political items were posed to the student cohort, and several of them offered very limited response options or were posed only in selected waves. The only seven-point item included in 1965 was party identification $(1=$ strong Democrat; $7=$ strong Republican). Six additional seven-point items were posed in all of the waves except 1965: selfreported ideological identification $(1=$ liberal; $7=$ conservative), attitude toward government assistance to minorities ( $1=$ in favor; $7=$ opposed), attitude toward equality for women ( $1=$ in favor; $7=$ opposed), attitude toward marijuana legalization $(1=$ in favor; $7=$ opposed $)$, attitude toward jobs guaranteed by the government $(1=$ in favor; $7=$ opposed), and attitude toward the rights of the accused ( $1=$ in favor; $7=$ opposed). Table 1 presents mean attitudes on all these measures for every time point they were assessed in the MSS. Reading these means from left to right within each row thus tracks how the average score on each trait's sevenpoint scale changed across time in the MSS sample. Table 1 also reports difference-of-means tests (two-tailed $t$-tests) indicating whether these attitudes showed any statistically significant change $(p<.05)$ between time points. For example, in the first row of table 1 , we see a statistically significant difference between party ID in 1982 and 1973 and between 1997 and 1982.

At first blush, the MSS data seem to provide support for the belief that people tend to become more conservative with age. Reading across rows we see that six of the seven variables available for analysis shift significantly to the right as this cohort ages from 26 to 50 (and from 18 to 50 in the case of party identification, the one variable for which readings were taken in 1965). The one exception is attitudes toward equality for women that became significantly more favorable from age 26 in 1973 to age 50 in 1997 (a shift to the left of 1.05; for an explanation of why this issue may be different from the other variables, see Levendusky [2009]). Typical movement to the right on the six variables is around a half point on the sevenpoint scales, with a range from .35 on legalizing marijuana to .92 for providing rights for the accused.

In all cases the lion's share of this movement came between age 26 and 35 (i.e., from 1973 to 1982) rather than from age 35 to 50 (from 1982 to 1997). In fact, the only items for which there was a statistically significant shift to the right from age 35 to 50 was for party identification and self-reported ideological labels, and the substantive movement in these cases was modest (.15 for party identification and .10 for ideology). From age 35 to 50, the MSS cohort did not become significantly

Table 1. Political Attitudes across Time: MSS Subjects, 1965-97

\begin{tabular}{|c|c|c|c|c|c|c|c|c|}
\hline \multirow[b]{2}{*}{ Variable } & \multicolumn{2}{|c|}{1965} & \multicolumn{2}{|c|}{1973} & \multicolumn{2}{|c|}{1982} & \multicolumn{2}{|c|}{1997} \\
\hline & Mean & $N$ & Mean & $N$ & Mean & $N$ & Mean & $N$ \\
\hline Party ID & 3.48 & 925 & 3.57 & 929 & $3.81^{\star}$ & 907 & $3.96^{\star}$ & 922 \\
\hline Ideology & $\ldots$ & $\ldots$ & 3.78 & 816 & $4.23^{\star}$ & 826 & $4.33^{*}$ & 905 \\
\hline Minority assistance & $\ldots$ & $\ldots$ & 3.80 & 900 & $4.49^{\star}$ & 908 & 4.52 & 927 \\
\hline Role of women & $\ldots$ & $\ldots$ & 2.99 & 919 & $2.20^{*}$ & 923 & $1.94^{\star}$ & 927 \\
\hline Rights of accused & $\ldots$ & $\ldots$ & 3.42 & 884 & $4.44^{*}$ & 901 & $4.34^{\star}$ & 912 \\
\hline Guaranteed jobs & $\ldots$ & $\ldots$ & 4.35 & 858 & $4.86^{\star}$ & 878 & 4.78 & 893 \\
\hline Marijuana legalization & $\ldots$ & $\ldots$ & 4.07 & 911 & $4.42^{*}$ & 888 & 4.42 & 908 \\
\hline
\end{tabular}

Note. All variables are on a 1 (most liberal position) to 7 (most conservative) scale. MSS = Michigan Youth-Parent Socialization Panel Study.

* Statistically significant difference $(p<.05$, two-tailed $t$-test) from previous time point. 
more conservative on any of the five substantive seven-point issues included in the surveys. Indeed, in this time period they became slightly more liberal on the role of women and rights of the accused. The fact that the overall drift toward conservatism is evident only between 1973 and 1982 raises the distinct possibility that this shift may be attributable to period rather than aging effects. For example, the 1982 reading took place in the context of the Reagan era when America seemed to be shifting to the right - although it is also the case that 1982 was not a particularly good year for Republicans: they lost 27 House seats in the midterm elections and, owing largely to a recession, President Reagan's popularity had dropped to $40 \%$.

Be this as it may, the larger issue is that longitudinal data with a single cohort cannot separate aging from period effects (Firebaugh 1997; O’Brien 2011; Yang and Land 2013). Is the pattern of results presented in table 1 due to a universal rhythm of aging, or is it due to something unusual surrounding the period of time analyzed? In order to provide a partial answer to this question, we compare the MSS results with information on the changing climate of the times. More specifically, we present the attitudes of the MSS cohort alongside of the results of each of the American National Election Study (ANES) surveys conducted closest in time to the MSS data collection points, thereby making it possible to examine the degree to which the aging of the MSS sample is or is not consistent with mean attitudes of the country at about the same time when the MSS soundings were taken. We are able to perform this analysis for four of the measures included in table 1: party identification, ideological identification, attitudes on women's rights, and attitudes on minority assistance. The other three issues in table 1 did not have equivalent ANES seven-point items included at the necessary time points.

In panel $\mathrm{A}$ of table 2, we compare the mean attitudes for the MSS cohort (see table 1) with the mean for all ANES participants in the appropriate year. This practice makes it easier to parse age and period effects given that the full ANES data set allows us to establish the general change in attitudes across American society during the relevant timeframe. If MSS attitudes over the years merely move in sync with the full ANES data, it would be difficult to claim an independent effect for aging. If, however, they shift to the right more rapidly than does the national mood (as represented by the full ANES sample), the case that conservative orientations increase with aging is enhanced.

Table 2. Political Attitudes across Time: MSS/ANES Comparisons

\begin{tabular}{|c|c|c|c|c|c|c|c|c|}
\hline \multirow[b]{2}{*}{ Year } & \multicolumn{2}{|c|}{ Party ID } & \multicolumn{2}{|c|}{ Ideology } & \multicolumn{2}{|c|}{ Minority Assistance } & \multicolumn{2}{|c|}{ Women's Equality } \\
\hline & MSS & ANES & MSS & ANES & MSS & ANES & MSS & ANES \\
\hline
\end{tabular}

A: ANES entire sample

\begin{tabular}{lllllllll}
1965 & 3.48 & $3.26^{*}$ & $\ldots$ & $\ldots$ & $\ldots$ & $\ldots$ & $\ldots$ & $\ldots .29$ \\
1973 & 3.57 & 3.62 & 3.78 & $4.14^{*}$ & 3.80 & $4.24^{*}$ & 2.99 & $2.51^{*}$ \\
1982 & 3.81 & $3.46^{*}$ & 4.23 & 4.32 & 4.49 & 4.41 & $2.86^{*}$ \\
1997 & 3.96 & $3.68^{*}$ & 4.33 & 4.33 & 4.52 & $4.82^{*}$ & 1.94 & $2.24^{*}$ \\
\hline
\end{tabular}

B: ANES, age 21-29 (1974), age 33-41 (1982), age 45-53 (1996)

\begin{tabular}{lllllllll}
1965 & 3.48 & $3.18^{*}$ & $\ldots$ & $\ldots$ & $\ldots$ & $\ldots$ & $\ldots$ & $\ldots$ \\
1973 & 3.57 & 3.62 & 3.78 & 3.79 & 3.80 & 3.79 & 4.99 & 2.99 \\
1982 & 3.81 & $3.38^{\star}$ & 4.23 & 4.14 & 4.49 & 4.20 & $2.56^{\star}$ \\
1997 & 3.96 & 3.70 & 4.33 & 4.31 & 4.52 & $4.78^{*}$ & 1.94 & 2.02 \\
\hline
\end{tabular}

C: ANES, age 21-29 always

\begin{tabular}{lllllllll}
1965 & 3.48 & $3.18^{*}$ & $\ldots$ & $\ldots$ & $\ldots$ & $\ldots$ & $\ldots$ & $\ldots$ \\
1973 & 3.57 & 3.62 & 3.78 & 3.79 & 3.80 & 3.79 & 2.99 & 3.07 \\
1982 & 3.81 & $3.53^{*}$ & 4.23 & 4.21 & 4.49 & 4.27 & 2.20 & $2.56^{*}$ \\
1997 & 3.96 & $3.60^{*}$ & 4.33 & $3.98^{*}$ & 4.52 & 4.72 & 1.94 & 2.01 \\
\hline
\end{tabular}

Note. All variables are on a 1 (most liberal) to 7 (most conservative) scale. MSS $=$ Michigan Youth-Parent Socialization Panel Study. ANES $=$ American National Election Study.

* Statistically significant difference $(p<.05$, two-tailed $t$-test) between samples at same time point. 
The pattern for each of the four available variables is somewhat different. With regard to party identification, the MSS sample was consistently more Republican than the nation as a whole, but the gap does not appear to change much over the decades: in 1965, the MSS sample was .22 more Republican than the ANES sample, and in 1997 it was .28 more Republican, so there is little evidence of an agerelated rightward shift in relative party identification. The case for such a shift is marginally better for ideological selfreport. In 1973, when the MSS cohort was 26, it was significantly more liberal than the nation as a whole (3.78 to 4.14); by 1997 , when the cohort was 50 , it was no longer more (or less) liberal than the nation as a whole (4.33 to 4.33 ). Similar modest shifts to the right, relative to the national mood, occur for the two issue positions for which data are available. In 1973, the MSS sample was .44 more liberal than the full ANES sample on the issue of minority assistance; 24 years later it was only .30 more liberal. Similarly, the shift toward more liberal stances on women's equality between 1973 and 1997 was slightly less pronounced for the (aging) MSS sample (a drop of 1.05 from 2.99 to 1.94) than for the country as a whole (a drop of 1.27 from 3.51 to 2.24 ).

Looking across the four available measures in panel $\mathrm{A}$ of table 2, evidence for a conservatizing shift attributable to aging is modest. The aging of the MSS sample was accompanied by conservative shifts that were slightly greater (or in the case of attitudes toward women's equality, by liberal shifts that were slightly less) than movements for the country as a whole. Differences in movement between the age-affected and ageunaffected samples, however, are typically only about .2 or 3 on a scale of $1-7$.

We employed other variants of ANES data to provide baselines against which to compare attitudes of the MSS cohort, and we present them in panels $B$ and $C$ of table 2 . The first (panel B) identifies those in the ANES data set who were in the same age cohort as the MSS cohort at any given time. To be more specific, in panel B we compare the familiar MSS results not with the full ANES sample, as we did in panel A, but rather with only those ANES respondents who were between the ages of 21 and 29 in the 1974 ANES survey, 33 and 41 in the 1982 ANES survey, and 45 and 53 in the 1996 ANES survey. As such, these particular ANES respondents should reflect the age bracket into which the MSS respondents fell at each data point. Including this set of data has two advantages. First, it provides a validity check on the MSS cohort data (a large divergence between the two data sets might suggest an issue with the external validity of the MSS data). Second, differences in patterns of change between these two data sets could indicate generational effects. On the whole, the results look good for the MSS sample. Although occasionally (for four of the 13 pairs) significantly different from the comparable ANES age group at a comparable time, these differences are substantively quite modest and are as likely to be in a liberal as a conservative direction. More to the point, this comparison does little to strengthen the evidence of a connection between aging and conservatism.

In panel $\mathrm{C}$ of table 2, we compare the MSS cohort with only the ANES respondents who were 21-29 years old, regardless of the survey year. Thus, as we move from 1973 to 1982 to 1997 the MSS sample becomes ever older than the baseline 21-29-year-old ANES subset, a situation that could provide some additional information on the effects of aging. If conservatizing movements are being driven by aging, the gap between the MSS sample and the ANES "forever-young" subset should increase in the later data points (1982 and especially 1997) as the age gap grows.

As it turns out, this pattern is really only evident for ideological self-report for which no differences in the samples exist in either 1973 or 1982, but by 1997, when the MSS sample is 50 and the ANES subset is still in their twenties, the MSS cohort is significantly more conservative. For the other three variables, there is little change in the gap present in the early readings and the gap present in $1997 .^{1}$

\section{INDIVIDUAL-LEVEL RESULTS}

Aggregated statistics can be misleading even when presented in the context of control groups, so we next examine individuallevel patterns of change. In the interest of space, we do so only for one central variable of interest - ideological self-labeling which was the lone variable for which it appeared that a slight conservatizing tendency was present. We broke the seven-point scale of ideology into a three-point scale where liberals, including weak liberals, were one category, moderates were another category, and conservatives, including weak conservatives, were yet another category. We did this to make it possible to identify people who changed their ideological label from 1973 to 1997 as opposed to those who stayed the same (or moved in 1982 and came home in 1997). The results are broken down according to whether respondents in 1973 identified as liberals, moderates, or conservatives. They are presented in table 3.

At least for ideology, the results seem to comport with our expectations that stability is the norm but that when movement does occur it will usually be in a conservative direction. Forty-four percent of liberals stayed liberal, $48 \%$ of moderates stayed moderate, and fully two-thirds of conservatives stayed conservative over the course of a quarter century, so stability is common. When movement does occur with age, the bias is toward a more conservative ideological posture. This is apparent both in moderates, where those moderates who did

1. Results comparing the MSS cohort to ANES respondents who attended college can be found in table A.1 (tables A.1 and A.2 are available online). 
608 / More Conservative with Age? Johnathan C. Peterson, Kevin B. Smith, and John R. Hibbing

Table 3. Individual-Level Change in Self-Reported Ideology between 1973 and 1997: MSS Cohort

\begin{tabular}{|c|c|c|c|c|c|c|c|c|}
\hline & \multicolumn{2}{|c|}{ No Change } & \multicolumn{2}{|c|}{ Shifted to Moderate } & \multicolumn{2}{|c|}{ Shifted to Liberal } & \multicolumn{2}{|c|}{ Shifted to Conservative } \\
\hline & $\%$ & $N$ & $\%$ & $N$ & $\%$ & $N$ & $\%$ & $N$ \\
\hline Liberals & 44 & 145 & 22 & 72 & $\ldots$ & $\ldots$ & 34 & 113 \\
\hline Moderates & 48 & 184 & $\ldots$ & $\ldots$ & 13 & 49 & 39 & 148 \\
\hline Conservatives & 67 & 149 & 14 & 32 & 19 & 43 & . . & $\ldots$ \\
\hline Total & 51 & 478 & 11 & 104 & 10 & 92 & 28 & 261 \\
\hline
\end{tabular}

Note. Cohort changing or shifting self-reported ideological categories between 1973 and 1997. Total $N=935$.

change were three times more likely to become conservatives than to become liberals, as well as in the imbalance of ideological movement for liberals and conservatives: $34 \%$ of liberals at age 26 were conservatives at 50 , but only $19 \%$ of conservatives at 26 were liberals at 50 .

\section{GROWTH-MIXTURE MODELING RESULTS}

The previous section did not permit much in the way of systematic analysis of the nature of individual variation, focused only on one variable (self-reported ideology), and did not leverage model fitting. Therefore, we now use growth-mixture modeling (GMM) - a more sophisticated technique - to examine patterns of change across several of the political variables contained in the MSS data set. GMM allows for the identification of latent classes based on patterns found in repeated measures (Ram and Grimm 2009). As each of the items was measured repeatedly in the MSS, it is possible to use GMM to identify patterns regarding both attitude stability and the direction of individual-level attitudinal change.

Although GMM can be an exploratory exercise, we take a confirmatory analytical approach. We begin with the assumption that there are five general patterns of change possible, although the first three patterns actually are patterns of stability; namely, some people will start off conservative and remain conservative, some people will start off moderate and remain moderate, and some people will start off liberal and remain liberal. The next two are patterns of lability: people who change in a conservative direction, and people who change in a liberal direction. Essentially, what we did with the GMM is treat these as five latent classes for each item, then tested to see whether models with fewer latent classes better fit the data. Specifically, we constrained the model to five latent classes for each item, and then we used the Vuong-Lo-MendellRubin likelihood ratio test to decide whether the model was a better fit than a model with one less class. If the model was a better fit than the $K-1$ model $(p<.05)$, we then selected that model. If the model was not a better fit, we then ran the $K-1$ model to see whether the four-class model fit better than a three-class model. We continued this process until we found a model with a better fit than the model with one less class. We ran the analyses with MPlus version 7.1 (Muthén and Muthén 2017).

Table 4 reports the estimates of the proportion of the MSS cohort that falls into each category in the best fitting model. So, to take the case of the guaranteed jobs item, what table 4 shows is that the best fitting model consisted of two categories: people who maintained a conservative viewpoint on this issue (about $77.5 \%$ of the cohort) and people who moved in a liberal direction on this issue (22.5\%). While there is some variation from item to item, the overall pattern that emerges is that stability is more dominant than lability, with any shift more likely to be in a conservative direction. For example, on selfreported ideology (the first row of table 4), roughly threequarters of the MSS cohort is estimated to remain stable across the time span studied. Of the roughly $25 \%$ that did shift, about $21 \%$ moved in a conservative direction and only $4 \%$ in a liberal direction (the issue of guaranteed jobs is the big exception). In other words, the best fitting model suggests that if you started out conservative you stayed conservative (25\%), if you started liberal you stayed liberal (16.5\%), and if you started a moderate you stayed a moderate $(33 \%)$.

On average, roughly $75 \%$ of the MSS cohort exhibited stable attitudes across the seven items we were able to analyze (bottom row of table 4). Among those whose attitudes did shift, they were more than twice as likely to move in a conservative direction (17.4\%) as opposed to a liberal (7\%) direction. In sum, the more rigorous statistical analysis of individual-level patterns confirms the general aggregate patterns reported in table $3 .^{2}$

\section{CONCLUSION}

As a young man, George Babbitt, the eponymous protagonist of Sinclair Lewis's 1922 novel Babbitt, temporarily embraced a

2. The latent class means and slopes for each issue attitude are reported in table A.2. 
Table 4. Issue Attitudes: Growth-Mixture Models

\begin{tabular}{|c|c|c|c|c|c|c|}
\hline Issue & Stay Conservative & Stay Liberal & Stay Moderate & Move Conservative & Move Liberal & $p$ \\
\hline Ideology & .25309 & .16506 & .33012 & .21458 & .03714 & .0294 \\
\hline Party ID & .32956 & .45187 & $\ldots$ & .17327 & .04530 & $<.001$ \\
\hline Guaranteed jobs & .77479 & $\ldots$ & $\ldots$ & $\ldots$ & .22521 & $<.001$ \\
\hline Legalized marijuana & .36019 & .24432 & .30570 & .08974 & $\ldots$ & $<.001$ \\
\hline Minority assistance & .61130 & .21684 & $\ldots$ & .13841 & .03345 & $<.001$ \\
\hline Protect rights of the accused & .21677 & .17006 & $\ldots$ & .54491 & .06826 & .0449 \\
\hline Women's role & $\ldots$ & .68521 & .17241 & .06118 & .08120 & $<.001$ \\
\hline Average & .36367 & .27619 & .11546 & .17458 & .07008 & $\ldots$ \\
\hline
\end{tabular}

Note. Proportion of the sample classified into each latent class. Empty cells indicate the group was not represented in the best fitting model. The $p$-values are derived from the Vuong-Lo-Mendell-Rubin likelihood ratio test, with $p<.05$ meaning the model fit better than a model with one less latent class $(K-1)$.

nonconformist, socially liberal lifestyle that included dabbling in leftist politics. After some time, Babbitt gravitated toward a more conservative life with an appropriately conservative wife and friends. Although initially Lewis's fictional account seems consistent with the "people become more conservative with age" folk tenet, there is more to the story. Babbitt was bred, born, and raised in a conservative, conformity-driven midwestern world. His conservatism did indeed waver for a time in early adulthood, but it could be said that, rather than being marked by a gradual migration to conservatism, in terms of political orientation and social lifestyle, Babbitt went out much as he came into adulthood - with only an ephemeral dalliance in between.

This general pattern of consistency with occasional, mild conservatizing tendencies on those fairly rare instances when stability is not complete summarizes the results of our more systematic investigation into political change over the course of a lifetime. Our use of the most representative long-term longitudinal political data set available, attention to the direction of change, comparison with ANES baseline groups, and application of GMM allow us to make a modest but important emendation to both folk wisdom and previous scholarly work.

Of course, important caveats apply to this study. Most obviously, although the MSS is an incredible resource, it has full readings from just one cohort (18-year-olds in 1965) and partial readings from a second. Might these results have been different if they had been based on a cohort that did not come of age in the middle of the tumultuous 1960s? Information on a wider range of issue attitudes might also lead to different conclusion. In addition, change could well occur after age 50, subsequent to when the final wave of the MSS occurred for the student cohort. We certainly cannot rule out any possibilities, and, therefore, caution should be employed before generalizing these findings. The nearly contemporaneous ANES re- sults we present provide important historical context but are no substitute for multiple longitudinal data sets covering the entirety of adulthood - but hoping for such data sets to magically spring into existence is beyond fanciful. We are thankful for those longitudinal data that are available.

We find some evidence of age-driven movement toward the right for ideological self-report. Any apparent conservatizing movement by the (aging) MSS cohort for party identification and for attitudes toward minority assistance was largely accounted for by changes in the national mood, and attitudes toward the role of women became more liberal with increasing age. Lacking ANES data on attitudes toward rights of the accused, guaranteed jobs, and the legalization of marijuana, we do not know whether the MSS cohort's movement to the right on these issues between ages 26 and 35 was also matched by societal changes, although the fact that this shift did not continue from ages 35 to 50 suggests that this may well be the case. But, tables 3 and 4 show that, of those who shifted ideologies, many more moved toward conservatism than liberalism. Given that the variable that changes most with aging is not party identification or substantive issue stances but rather ideological self-labeling, one intriguing possibility is that aging may increase the likelihood of identifying as a conservative more than it leads people actually to be conservative (this might help explain, for example, why attitudes on the role of women moved leftward while overall ideological selfidentification moved in the opposite direction). Scholars have known for some time that Americans tend to self-report being conservative even as many simultaneously endorse liberal issue positions (e.g., Ellis and Stimson 2012). We know of no evidence that the disjunction between operational and selfreported ideology increases with age, but our results suggest there may be value in pursuing this possibility.

If those who are not liberal at 20 have no hearts and those who are not conservative at 30 have no brains, there are many 
people in this world without either hearts or brains. The nature of attitudinal change through the life span is more nuanced than conventional wisdom and previous scholarship suggests. Whether it is because of genetics (e.g., Alford, Funk, and Hibbing 2005), powerful early socialization (e.g., Easton and Dennis 1980; Hess and Torney 1967), or the impressionable nature of late adolescence and early adulthood (e.g., Alwin et al. 1991), we find that existing political science research is correct in emphasizing the stability of political orientations over the course of the life span. Acknowledgment of this stability, however, should not be so complete as to blind us to the fact that, as is so often the case, folk wisdom contains a glimmer of truth.

\section{ACKNOWLEDGMENTS}

We would like to thank the members of the University of Nebraska Political Behavior Reading Group for their incisive comments on numerous previous drafts of this article. We would also like to thank Jacob Cheadle for discussions that vastly improved the methodological section of this article. Conference discussants at the Midwest Political Science Association and our anonymous reviewers also deserve our thanks for their incisive comments on earlier drafts.

\section{REFERENCES}

Achen, Christopher H. 2002. "Parental Socialization and Rational Party Identification." Political Behavior 24 (2): 151-70.

Achen, Christopher H., and Larry M. Bartels. 2016. Democracy for Realists: Why Elections Do Not Produce Responsive Government. Princeton, NJ: Princeton University Press.

Alford, John R., Carolyn L. Funk, and John R. Hibbing. 2005. "Are Political Orientations Genetically Transmitted?" American Political Science Review 99 (2): 153-67.

Alwin, Duane F. 1994. “Aging, Personality, and Social Change: The Stability of Individual Differences over the Adult Lifespan.” In David L. Featherman, Richard M. Lerner, and Marion Perlmutter, eds., Lifespan Development and Behavior, vol. 12. Hillsdale, NJ: Erlbaum, 135-85.

Alwin, Duane F., Ronald L. Cohen, and Theodore M. Newcomb. 1991. Political Attitudes over the Lifespan. Madison: University of Wisconsin Press.

Alwin, Duane F., and Jon A. Krosnick. 1991. "Aging, Cohorts, and the Stability of Sociopolitical Orientations over the Life Span." American Journal of Sociology 97 (1): 169-95.

Angel, Jacqueline L., and Richard A. Settersten. 2012. "The New Realities of Aging: Social and Economic Contexts." In Linda J. Waite and Thomas J. Plewes, eds., New Directions in Social Demography, Social Epidemiology, and the Sociology of Aging. Washington, DC: National Academies.

Campbell, Andrea Louise. 2002. "Self-Interest, Social Security, and the Distinctive Participation Patterns of Senior Citizens." American Political Science Review 96:565-74.

Campbell, Angus, Philip E. Converse, Warren E. Miller, and Donald E. Stokes. 1960. The American Voter. Chicago: University of Chicago Press.

Converse, Philip E. 1964. “The Nature of Belief Systems in Mass Publics.” In David E. Apter, ed., Ideology and Its Discontents. New York: Free Press.

Cornelis, Ilse, Alain Van Hiel, Arne Roets, and Malgorzata Kossowska. 2009. "Age Differences in Conservatism: Evidence on the Mediating
Effects of Personality and Cognitive Style." Lournal of Personality 77 (1): 51-88.

Danigelis, Nicholas L., Melissa Hardy, and Stephen J. Cutler. 2007. "Population Aging, Intracohort Aging, and Sociopolitical Attitudes.” American Sociological Review 72 (5): 812-30.

Dennis, N. A., S. M. Hayes, S. E. Prince, D. J. Madden, S. A. Huettel, and R. Cabeza. 2008. "Effects of Aging on the Neural Correlates of Successful Item and Source Memory Encoding." Lournal of Experimental Psychology: Learning, Memory, and Cognition 34 (4): 791-808.

Dinas, Elias. 2013. “Opening 'Openness to Change': Political Events and the Increased Sensitivity of Young Adults." Political Research Quarterly 66 (4): 868-82.

Easton, David, and Jack Dennis. 1980 Children in the Political System: Origins of Political Legitimacy. New York: McGraw-Hill.

Ellis, Christopher, and James A. Stimson. 2012. Ideology in America. New York: Cambridge University Press.

Fiorina, Morris P. 1981. Retrospective Voting in American National Elections. New Haven, CT: Yale University Press.

Firebaugh, Glenn. 1997. Distinguishing Age, Period, and Cohort Effects. Beverly Hills, CA: Sage.

Franklin, Charles H. 1984. "Issue Preferences, and the Evolution of Party Identification." American Journal of Political Science 28 (3): 459-78.

Franklin, Charles H, and John E. Jackson. 1983. "The Dynamics of Party Identification.” American Political Science Review 77 (4): 957-73.

Franssen, Vicky, Kristof Dhont, and Alain Van Hiel. 2013. "Age-Related Differences in Ethnic Prejudice: Evidence of the Mediating Effect of Right-Wing Attitudes." Lournal of Community and Applied Social Psychology 23 (3): 252-57.

Gerber, Alan S., and Donald P. Green. 1998. "Rational Learning and Partisan Attitudes." American Journal of Political Science 42 (3): 794-818.

Gerber, Alan S., Gergory A. Huber, David Doherty, Conor M. Dowling, and Shang E. Ha. 2010. "Personality and Political Attitudes: Relationships across Issue Domains and Political Contexts.” American Political Science Review 104 (1): 111-33.

Glenn, Norvall D. 1974. “Aging and Conservatism.” Annals of the American Academy of Political and Social Science 415 (1): 176-86.

Grant, Malcolm J., Abraham S. Ross, Cathryn M. Button, T. Edward Hannah, and Rhoda Hoskins. 2001. "Attitudes and Stereotypes about Attitudes across the Lifespan." Social Behavior and Personality: An International Journal 29 (8): 749-62.

Green, Donald P., and Ron Shachar. 2000. "Habit Formation and Political Behaviour: Evidence of Consuetude in Voter Turnout." British Journal of Political Science 30 (4): 561-73.

Henry, P. J., and David O. Sears. 2009. "The Crystallization of Contemporary Racial Prejudice across the Life Span.” Political Psychology 30 (4): 569-90.

Hess, Robert D., and Judith V. Torney. 1967. The Development of Political Attitudes in Children. Chicago: Aldine.

Hibbing, John R., Kevin G. Smith, and John R. Alford. 2014. Predisposed: Liberals, Conservatives, and the Biology of Political Differences. New York: Routledge.

Jennings, M. Kent, and Gregory B. Markus. 1984. "Partisan Orientations over the Long Haul: Results from the Three-Wave Political Socialization Panel Study." American Political Science Review 78 (4): 1000-1018.

Jennings, M. Kent, Gregory B. Markus, Richard G. Niemi, and Laura Stoker. 2005. "Youth-Parent Socialization Panel Study, 1965-1997: Four Waves Combined." Inter-university Consortium for Political and Social Research, Ann Arbor, MI. https://doi.org/10.3886/ICPSR04037.v1.

Jennings, M. Kent, and Richard G. Niemi. 1981. Generations and Politics: A Panel Study of Young Adults and Their Parents. Princeton, NJ: Princeton University Press. 
Jennings, M. Kent, Laura Stoker, and Jake Bowers. 2009. "Politics across Generations: Family Transmission Reexamined." Journal of Politics 71 (3): 782-99.

Jost, John T., J. Glaser, Arie W. Kruglanski, and F. J. Sulloway. 2003. "Political Conservatism as Motivated Social Cognition." Psychological Bulletin 129 (3): 339-765.

Jost, John T., Jaime L. Napier, Hulda Thorisdottir, Samuel D. Gosling, Tibor P. Palfai, and Brian Ostafin. 2007. "Are Needs to Manage Uncertainty and Threat Associate with Political Conservatism or Ideological Extremity?" Personality and Social Psychology Bulletin 33 (7): 989-1007.

Kossowska, Małgorzata, Katarzyna Jaśko, and Yoram Bar-Tal. 2012. “Need for Closure and Cognitive Structuring among Younger and Older Adults." Polish Psychological Bulletin 43 (1): 40-49.

Levendusky, Matthew. 2009. The Partisan Sort. Chicago: University of Chicago Press.

Markus, Gregory B. 1979. “The Political Environment and the Dynamics of Public Attitudes: A Panel Study." American Journal of Political Science 23 (2): 338-59.

Mondak, Jeffery J. 2010. Personality and the Foundations of Political Behavior. New York: Cambridge University Press.

Muthén, Linda K. and Bengt O. Muthén. 2017. Mplus User's Guide: Statistical Analysis with Latent Variables. 8th ed. Los Angeles: Muthén \& Muthén.

Newcomb, Theodore M. 1943. Personality and Social Change: Attitude Formation in a Student Community. New York: Dryden.

Newcomb, Theodore M., Katheryne Koenig, Richard Flacks, and Donald P. Warwick. 1967. Persistence and Change: Bennington College and Its Students after Twenty-Five Years. New York: Wiley.

Niemi, Richard G., and M. Kent Jennings. 1991. "Issues and Inheritance in the Formation of Party Identification." American Journal of Political Science 35 (4): 970-88.

O'Brien, Robert M. 2011. "The Age-Period-Cohort Conundrum as Two Fundamental Problems." Quality and Quantity 45 (6): 1429-44.

Pabayo, Roman, Ichiro Kawachi, and Peter Muennig. 2015. "Political Party Affiliation, Political Ideology, and Mortality." Journal of Epidemiology and Community Health 69 (5): 423-31.

Page, Benjamin I., and Robert Y. Shapiro. 1992. The Rational Public: Fifty Years of Trends in Americans' Policy Preferences. Chicago: University of Chicago Press.

Ram, Nilam, and Kevin J. Grimm. 2009. "Methods and Measures: Growth Mixture Modeling; A Method for Identifying Differences in Longitudinal Change among Unobserved Groups." International Journal of Behavioral Development 33 (6): 565-76.

Schwadel, Philip, and Christopher R. H. Garneau. 2014. "An Age-PeriodCohort Analysis of Political Tolerance in the United States.” Sociological Quarterly 55:421-52.
Searing, Donald, Gerald Wright, and George Rabinowitz. 1976. "The Primacy Principle: Attitude Change and Political Socialization.” British Journal of Political Science 6:83-113.

Sears, David. 1981. "Life-Stage Effects on Attitude Change, Especially among the Elderly.” In Sara Kiesler, James N. Morgan, and Valerie K. Oppenheimer, eds., Aging: Social Change. New York: Academic Press, 183-204.

Sears, David O., and Carolyn L. Funk. 1999. "Evidence of the Long-Term Persistence of Adults' Political Predispositions.” Lournal of Politics 61 (1): 1-28.

Sears, David O., and Nicholas A. Valentino. 1997. "Politics Matters: Political Events as Catalysts for Preadult Socialization.” American Political Science Review 91 (1): 45-65.

Soto, C. J., Oliver P. John, Samuel D. Gosling, and J. Potter. 2011. “Age Differences in Personality Traits from Ages 10 to 65.” Lournal of Personality and Social Psychology 100 (2): 330-48.

Srivastava, Sanjay, Oliver P. John, Samuel D. Gosling, and J. Potter. 2003. "Development of Personality in Early and Middle Adulthood." Lournal of Personality and Social Psychology 84 (5): 1041-53.

St. Jacques, Peggy L., Florin Dolcos, and Roberto Cabeza. 2009. "Effects of Aging on Functional Connectivity of the Amygdala for Subsequent Memory of Negative Pictures.” Psychological Science 20 (1): 74-84.

Stoker, Laura, and M. Kent Jennings. 2008. "Of Time and the Development of Partisan Polarization.” American Journal of Political Science 52 (3): $619-35$.

Subramanian, S. V., Tsuyoshi Hamano, Jessica M. Perkins, Akio Koyabu, and Yoshikazu Fujisawa. 2010. "Political Ideology and Health in Japan: A Disaggregated Analysis." Lournal of Epidemiology and Community Health 64 (9): 838-40.

Subramanian, S. V., Tim Huijts, and Jessica M. Perkins. 2009. “Association between Political Ideology and Health in Europe." European Journal of Public Health 19 (5): 455-57.

Tilley, James, and Geoffrey Evans. 2014. "Ageing and Generational Effects on Vote Choice: Combining Cross-Sectional and Panel Data to Estimate APC Effects.” Electoral Studies 33:19-27.

Van Hiel, Alain, and Lieven Brebels. 2011. "Conservatism Is Good for You: Cultural Conservatism Protects Self-Esteem in Older Adults.” Personality and Individual Differences 50 (1): 120-23.

Walsh, Katherine Cramer, M. Kent Jennings, and Laura Stoker. 2004 “The Effects of Social Class Identification on Participatory Orientations towards Government." British Journal of Political Science 34 (3): 469-95.

Wilson, Glenn D. 1973. The Psychology of Conservatism. New York: Academic Press.

Yang, Yang, and Kenneth C. Land. 2013. Age-Period-Cohort Analysis. New York: Chapman \& Hall.

Zaller, John R. 1992. The Nature and Origins of Mass Opinion. New York: Cambridge University Press. 


\section{APPENDIX}

Table A.1 Political Attitudes Across Time: MSS/ANES Comparison (ANES COLLEGE ONLY)

\begin{tabular}{|l|l|l|l|l|l|l|l|l|}
\hline & \multicolumn{2}{|c|}{ Party ID } & \multicolumn{2}{c|}{ Ideology } & \multicolumn{2}{c|}{ Minority Assistance } & \multicolumn{2}{c|}{ Women's Equality } \\
\hline Year & MSS & ANES & MSS & ANES & MSS & ANES & MSS & ANES \\
\hline $\mathbf{1 9 6 5}$ & 3.48 & $3.97^{*}$ & -- & -- & -- & -- & -- & - \\
\hline $\mathbf{1 9 7 3}$ & 3.57 & $4.14^{*}$ & 3.78 & $3.97^{*}$ & 3.80 & 3.74 & 2.99 & $2.65^{*}$ \\
\hline $\mathbf{1 9 8 2}$ & 3.81 & 3.85 & 4.23 & 4.11 & 4.49 & $4.02^{*}$ & 2.20 & 2.18 \\
\hline $\mathbf{1 9 9 7}$ & 3.96 & 4.08 & 4.33 & $\begin{array}{l}4.17(\mathrm{p}= \\
.0523)\end{array}$ & 4.52 & 4.65 & 1.94 & 1.92 \\
\hline
\end{tabular}

*Statistically significant difference ( $p<.05$, two-tailed t-test) between samples at same time point All variables are on a 1 (most liberal) to 7 (most conservative) scale MSS=Michigan Youth Parent Socialization Study ANES=American National Election Study, subjects who attended college 
Table A.2: Issue Attitudes Latent Class Means and Slopes

\begin{tabular}{|c|c|c|c|c|}
\hline $\begin{array}{l}\text { Issue Attitude } \\
\& \text { Latent Class }\end{array}$ & $\begin{array}{l}\text { Mean (s.e.) at } \\
\text { Time } 1\end{array}$ & $\begin{array}{l}p \text {-value of } \\
\text { Mean }\end{array}$ & Slope (s.e.) & $\begin{array}{l}p \text {-value of } \\
\text { Slope }\end{array}$ \\
\hline Ideology SC & $5.05(.297)$ & $<.001$ & $.207(.062)$ & $<.001$ \\
\hline Ideology SL & $2.56(.122)$ & $<.001$ & $-.023(.048)$ & .63 \\
\hline Ideology SM & $3.85(.107)$ & $<.001$ & $.052(.04)$ & .19 \\
\hline Ideology MC & $3.42(.215)$ & $<.001$ & $.789(.105)$ & $<.001$ \\
\hline Ideology ML & $4.90(.242)$ & $<.001$ & $-.894(.100)$ & $<.001$ \\
\hline PID SC & $4.90(.117)$ & $<.001$ & $.197(.03)$ & $<.001$ \\
\hline PID SL & $2.72(.08)$ & $<.001$ & $-.138(.017)$ & $<.001$ \\
\hline PID MC & $1.96(.18)$ & $<.001$ & $.984(.052)$ & $<.001$ \\
\hline PID ML & $6.13(.339)$ & $<.001$ & $-.895(.10)$ & $<.001$ \\
\hline Jobs SC & $4.45(.08)$ & $<.001$ & $.299(.038)$ & $<.001$ \\
\hline Jobs ML & $4.85(.218)$ & $<.001$ & $-.592(.083)$ & $<.001$ \\
\hline Marijuana SC & $6.72(.032)$ & $<.001$ & $-.529(.042)$ & $<.001$ \\
\hline Marijuana SL & $1.29(.04)$ & $<.001$ & $.514(.049)$ & $<.001$ \\
\hline Marijuana SM & $3.90(.052)$ & $<.001$ & $.270(.046)$ & $<.001$ \\
\hline Marijuana MC & $1.60(.115)$ & $<.001$ & $1.537(.102)$ & $<.001$ \\
\hline $\begin{array}{l}\text { Minority Asst. } \\
\text { SC }\end{array}$ & $4.73(.126)$ & $<.001$ & $.084(.059)$ & $<.001$ \\
\hline $\begin{array}{l}\text { Minority Asst. } \\
\text { SL }\end{array}$ & $2.68(.192)$ & $<.001$ & $.136(.075)$ & .07 \\
\hline $\begin{array}{l}\text { Minority Asst. } \\
\text { MC }\end{array}$ & $3.00(.20)$ & $<.001$ & $.967(.111)$ & $<.001$ \\
\hline $\begin{array}{l}\text { Minority Asst. } \\
\text { ML }\end{array}$ & $5.34(.344)$ & $<.001$ & $-1.079(.272)$ & $<.001$ \\
\hline $\begin{array}{l}\text { Accused } \\
\text { Rights SC }\end{array}$ & $5.43(.156)$ & $<.001$ & $.057(.066)$ & .39 \\
\hline $\begin{array}{l}\text { Accused } \\
\text { Rights SL }\end{array}$ & $2.33(.174)$ & $<.001$ & $-.020(.08)$ & .80 \\
\hline $\begin{array}{l}\text { Accused } \\
\text { Rights MC }\end{array}$ & $3.11(.226)$ & $<.001$ & $.677(.105)$ & $<.001$ \\
\hline $\begin{array}{l}\text { Accused } \\
\text { Rights ML }\end{array}$ & $5.20(.299)$ & $<.001$ & $-.921(.191)$ & $<.001$ \\
\hline $\begin{array}{l}\text { Women's Role } \\
\text { SL }\end{array}$ & $2.06(.076)$ & $<.001$ & $-.308(.026)$ & $<.001$ \\
\hline $\begin{array}{l}\text { Women's Role } \\
\text { SM }\end{array}$ & $3.66(.162)$ & $<.001$ & $-.020(.063)$ & .75 \\
\hline $\begin{array}{l}\text { Women's Role } \\
\text { MC }\end{array}$ & $4.05(.547)$ & $<.001$ & $.547(.110)$ & $<.001$ \\
\hline $\begin{array}{l}\text { Women's Role } \\
\text { ML }\end{array}$ & $5.14(.211)$ & $<.001$ & $-1.43(.095)$ & $<.001$ \\
\hline
\end{tabular}


Scales for all items range from 1-7. Standard errors are in parentheses. Positive slopes indicate change in a conservative direction. Negative slopes indicate change in a liberal direction. 